\title{
Múltiplos cornos cutâneos em coxins palmares e plantares de um gato persa
}

\author{
Multiple cutaneous horns on the footpads of a persian cat \\ Heloisa Justen Moreira de Souza ${ }^{\mathrm{I}}$ Fernanda Vieira Amorim da Costa ${ }^{\mathrm{II}}$ Otávia Dorigon ${ }^{\mathrm{III}}$ \\ Cristiane Brandão Damico ${ }^{\mathrm{IV}}$ Marilene de Farias Brito ${ }^{\mathrm{V}}$
}

\section{RESUMO}

Cornos cutâneos são infrequentes em gatos, principalmente em felinos jovens. Neste trabalho, é relatado um caso de um felino da raça Persa, macho, com oito meses de idade e apresentando histórico de espirros. Ao exame clínico, identificaram-se projeções corniformes originadas nos coxins palmares e plantares. A avaliação histológica de biópsia excisional demonstrou hiperqueratose densa, com numerosos queratinócitos sobre epiderme hiperplásica, não sendo identificado nenhum grau de malignidade. Não foi constatada a associação das lesões com a infecção pelo vírus da leucemia felina. O tratamento instituído incluiu excisão parcial mensal dos cornos cutâneos e acompanhamento clínico do animal.
\end{abstract}

- NOTA -
Palavras-chave: chifres cutâneos, felino.

\section{ABSTRACT}

Cutaneous horns are seldom seen in cats, especially in young ones. A case of a Persian cat, male, eight months old, with a history of sneezes is described. During physical examination, multiple horns on the all footpads were noticed. The histopathological diagnosis of excisional biopsy was dense hyperkeratosis, with numerous keratinocytes above hyperplastic epidermis and no evidence of malignity. There was no association between the lesions and infection with leukemia virus. The treatment was mensal trimming off the cutaneous horns and clinical follow up of the animal.

Key words: cutaneous horns, feline.
Os cornos cutâneos são crescimentos córneos compostos de queratina (SOUZA et al., 2003) e encontrados em diversas espécies domésticas e no homem (YAGER \& SCOTT, 1992; SOUZA et al., 1999). Mais de $60 \%$ são benignos; porém, lesões pré-malignas e malignas podem ser associadas aos cornos cutâneos (YU et al., 1991). Cabeça, escroto, região mamária e membros são os locais de maior incidência, podendo haver ou não lesões concomitantes na pele dos animais (YAGER \& SCOTT, 1992; SOUZA et al., 1999). A etiologia da doença ainda não foi completamente elucidada; contudo, acredita-se que os cornos são oriundos de papilomas, carcinomas de células escamosas ou outras disqueratoses (YAGER \& SCOTT, 1992). Os cornos cutâneos são pouco frequentes em gatos e, quando presentes, geralmente estão associados à infecção pelo vírus da leucemia felina (FeLV) ou ao vírus do sarcoma felino (YAGER \& SCOTT, 1992). São projeções firmes, circunscritas e semelhantes a cornos. Podem apresentar variações de tamanho (de milímetros a centímetros) e formato, com formas cilíndricas, cônicas, angulares, retas e helicoidais, e coloração amarela, marrom ou cinza. A superfície do corno pode ser macia e polida, ou

'Departamento de Patologia Clínica e Cirúrgica, Universidade Federal Rural do Rio de Janeiro (UFRRJ), 23890-000, Seropédica, RJ, Brasil. E-mail: justen@centroin.com.br. Autor para correspondência.

"Programa de Pós-graduação em Ciências Veterinárias, Faculdade de Veterinária, Universidade Federal do Rio Grande do Sul (UFRGS), Porto Alegre, RS, Brasil.

"I'Médica Veterinária Autônoma, Clínica Veterinária do Gato, Porto Alegre, RS, Brasil.

Iv Médica Veterinária Autônoma, Clínica Veterinária Gatos \& Gatos Vet, Rio de Janeiro, RJ, Brasil.

v'Departamento de Epidemiologia e Saúde Pública, UFRRJ, Seropédica, RJ, Brasil. 
enrugada e áspera (REES \& GOLDSCHIMIDT, 1998; SOUZA et al., 1999). Geralmente, a pele ao redor do corno forma uma dobra (YAGER \& SCOTT, 1992). A base do corno deve ser sempre inspecionada para identificar uma possível causa subjacente. Na avaliação histológica, eles são constituídos por camadas concêntricas de células epiteliais corneificadas (MICHAL et al., 2002). O tratamento definitivo consiste na excisão cirúrgica, podendo ocorrer recidivas (SOUZA et al., 1999; COPCU et al., 2004).

Um felino da raça Persa, macho, com oito meses de idade e pesando $3,530 \mathrm{~kg}$ foi atendido no Hospital Veterinário da Universidade Federal Rural do Rio de Janeiro, tendo como queixa principal espirros. Ao exame clínico, observou-se a presença de múltiplas projeções corniformes originadas dos coxins palmares e plantares (Figura 1). A responsável pelo animal relatou a existência destes desde os três meses de idade, momento em que começou a conviver com o gato. Tais projeções eram semelhantes a chifres de coloração castanho, com tamanhos que variavam de $0,4 \mathrm{~cm}$ a $1,4 \mathrm{~cm}$ de comprimento por 0,3cm a 0,4cm de diâmetro (Figura 1). À palpação, os cornos eram indolores e não havia qualquer lesão em sua base. O teste imunoenzimático ELISA para detectar antígeno do vírus da leucemia felina e anticorpo para o vírus da imunodeficiência felina foi negativo. A biopsia excisional da lesão foi realizada para obtenção do diagnóstico definitivo. A avaliação histológica demonstrou uma hiperqueratose densa, com numerosos queratinócitos sobre epiderme hiperplásica, não sendo identificado nenhum grau de malignidade (Figura 2). A proprietária optou por um tratamento conservador constituído de excisões parciais mensais das projeções córneas, viabilizando o controle clínico dessa afecção. O diagnóstico clínico de Complexo Respiratório Viral Felino (CRVF) foi realizado com base nos sinais de infecção no trato respiratório superior em um gato jovem. Desse modo, o animal foi submetido ao tratamento com Interferon a 2( Recombinante Humano ${ }^{\mathrm{a}}$, na dosagem de 30UI gato-1, por via oral, durante 20 dias, diariamente.

Cornos cutâneos têm sido associados à infecção pelo vírus da leucemia felina (FeLV), sarcoma felino (YAGER \& SCOTT, 1992), papilomas, tricoblastomas, carcinomas de células escamosas, cistos foliculares, acantomas queratinizantes infundibulares ou queratoses actínicas (MEDLEAU \& HNILICA, 2003); porém, em alguns casos, tais doenças não são identificadas (SOUZA et al., 1999). Não há relatos, na literatura, da associação de cornos cutâneos ao CRVF. Neste relato, não houve nenhuma evidência

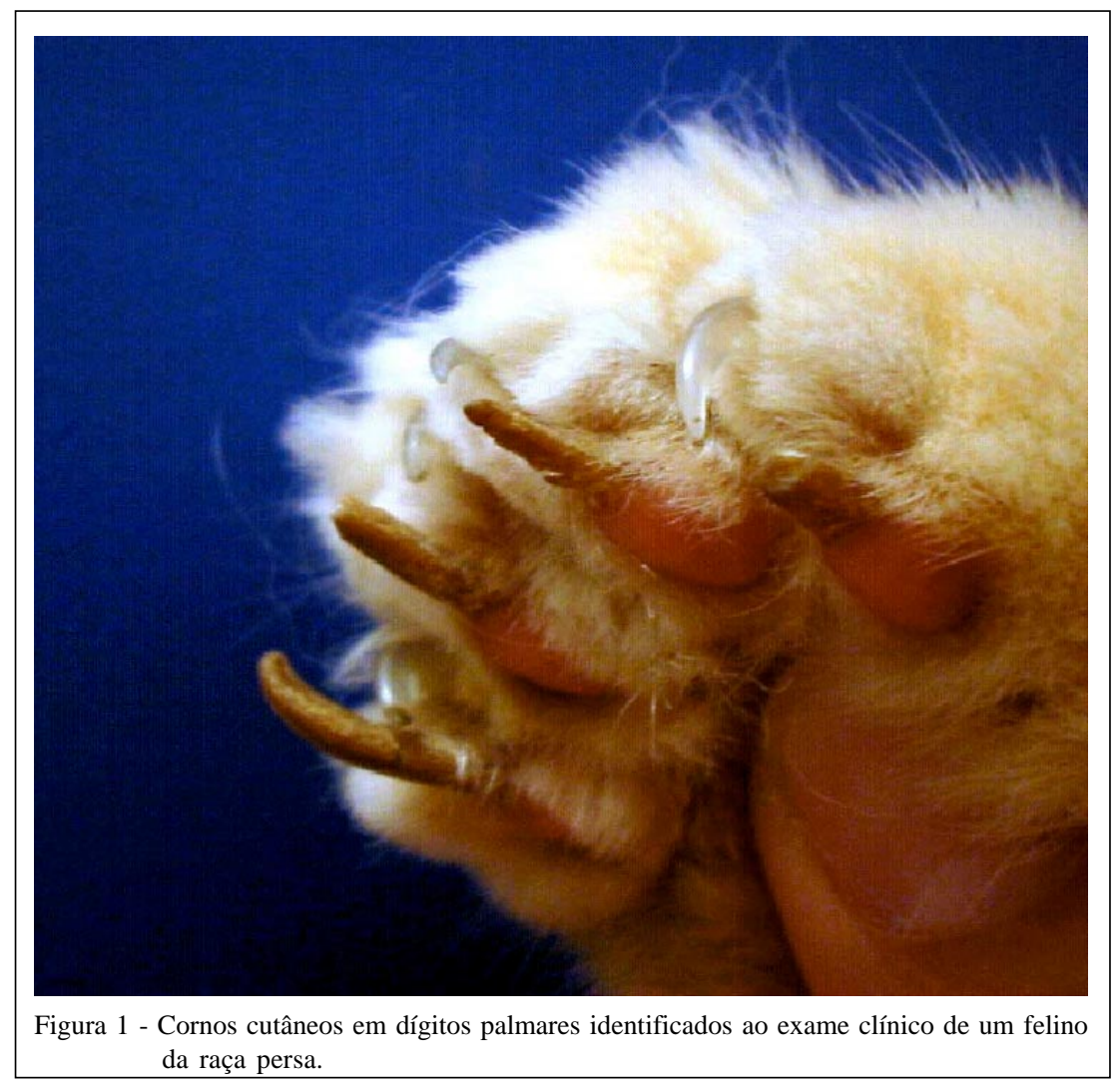

Ciência Rural, v.40, n.3, mar, 2010. 


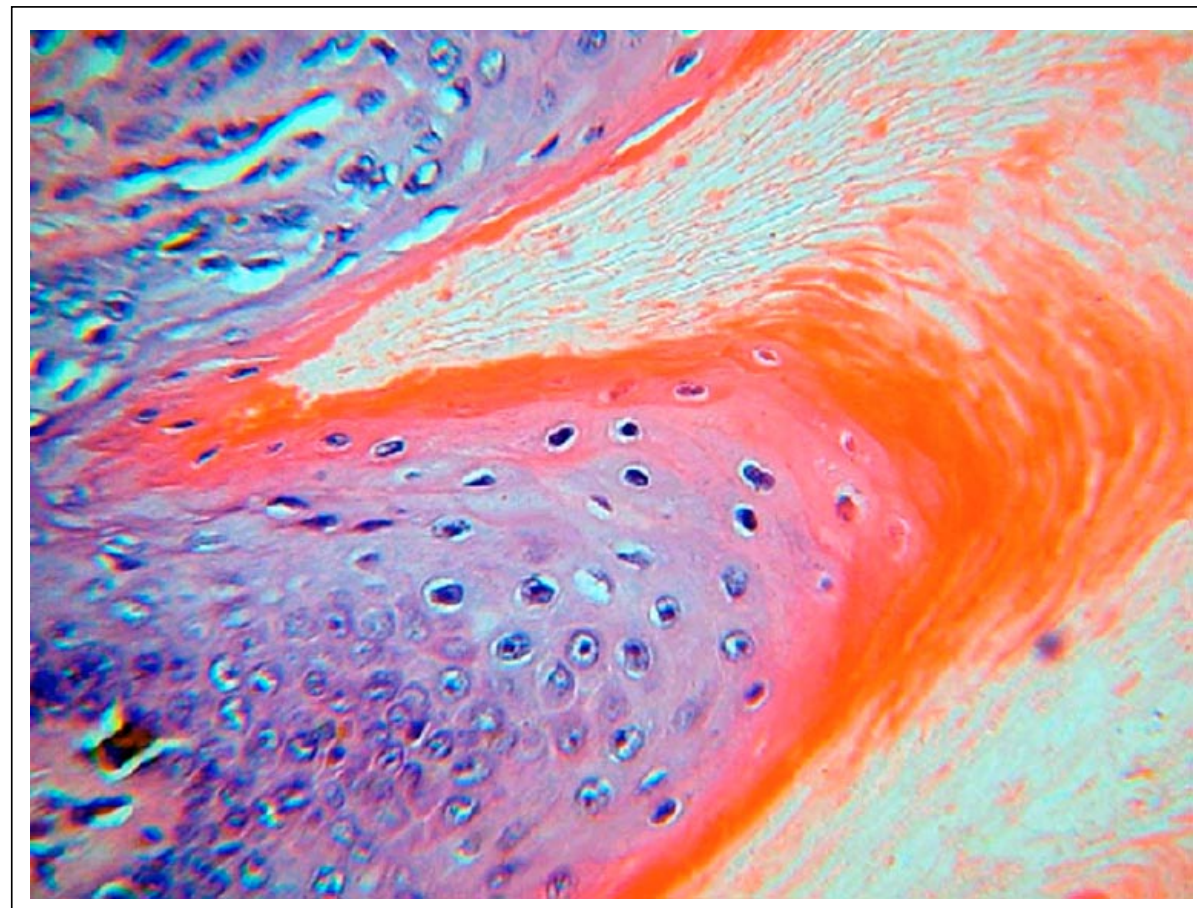

Figura 2 - Fotomicrografia. Hiperqueratose extensa, compacta e laminada com numerosos queratinócitos. (H\&E - 100X original) em dígitos palmares de um felino da raça persa.

de infecção por vírus da leucemia felina ou neoplasia. Cornos cutâneos não são frequentes em gatos, principalmente em felinos jovens (CENTER et al., 1982; REES \& GOLDSCHIMIDT, 1998). Nesse caso, poderse-ia sugerir uma origem congênita (SOUZA et al., 1999).

Histologicamente há hiperqueratose extensa e compacta da lâmina, mas a base das lesões é caracterizada por paraqueratose, apoptose e células gigantes multinucleadas queratinocíticas. Lesões abaixo das unhas podem ser vistas em gatos FeLVnegativos e têm diferentes características histológicas (LITTLEWOOD, 2008). A avaliação histopatológica revelou uma desordem benigna, corroborando o estudo de COPCU et al. (2004), os quais afirmaram que os cornos cutâneos são predominantemente benignos. Apesar de os cornos cutâneos poderem ocorrer em vários locais, é importante lembrar que, nos gatos, estes apresentam localização regular nos coxins, podendo ocorrer em coxins palmares e plantares (REES \& GOLDSCHIMIDT, 1998; SOUZA et al., 1999).

Se as lesões causadas pelos cornos cutâneos estiverem nas superfícies plantares, podem causar desconforto ao caminhar (WOLF, 2008) e alterar a marcha do gato; dessa forma, o responsável do animal pode perceber a presença da lesão (REES \& GOLDSCHIMIDT, 1998; SOUZA et al., 1999).
Em face da raridade de relatos dessa enfermidade, este estudo contribui por meio da descrição de um caso de corno cutâneo de origem desconhecida em um felino, sendo sugerida uma origem congênita. Não foi constatada a presença de lesão cutânea maligna ou associação com a infecção pelo vírus da leucemia felina, representando, dessa forma, um prognóstico favorável ao paciente.

\section{FONTE DE AQUISIÇÃO}

a - Blauferon-B ${ }^{\circledR} 3$ M.U.I., Blausiegel, Cotia - SP

\section{REFERÊNCIAS}

CENTER, S.A. et al. Multiple cutaneus horns on the foot pads of a cat. Feline Practice, v.12, n.4, p.26-30, 1982.

COPCU, E. et al. Cutaneous horns: Are these lesions as innocent as they seem to be? World Journal of Surgical Oncology, v.3, n.2, p.18, 2004.

LITTLEWOOD, J.D. Feline viral dermatoses. In: BRITISH SMALL ANIMAL VETERINARY CONGRESS, 2008, Birmingham, UK. Proceedings... Disponível em: <http:// w w w. vi n . c o m/ M e m b e r s / P r o c e eding s/ Proceedings.plx?CID=bsava2008\&PID=pr20140\&O=VIN $>$. Acesso: 16 nov. 2009.

Ciência Rural, v.40, n.3, mar, 2010. 
MEDLEAU, L.; HNILICA, K.A. Dermatologia de pequenos animais - Atlas colorido e guia terapêutico. São Paulo: Roca, 2003. 353p.

MICHAL, M. et al. Gigantic cutaneous horns of the scalp. Lesions with a gross similarity to the horns of animals: A report of four cases. American Journal of Surgical Pathology, v.26,n.6, p.789-794, 2002.

REES, C.A.; GOLDSCHMIDT, M.H. Cutaneus horn and squamous cell carcinoma in situ (Bower's disease). Journal of the American Animal Hospital Association, v.34, n.6, p.485-486, 1998.

SOUZA, E.L. et al. Cornos cutâneos nos coxins palmares e plantares em um gato. In: CONGRESSO INTERNACIONAL DE MEDICINA FELINA, 1999, Rio de Janeiro, RJ. Proceedings... Rio de Janeiro: Colégio Brasileiro de Cirurgiões, 1999. p.17.
SOUZA, L.N. et al. Cutaneous horn occurring on the lip of a child. International Journal of Paediatric Dentistry, v.13, n.5, p.365-367, 2003.

WOLF, A.M. What's wrong with that foot? In: ATLANTIC COAST VETERINARY CONFERENCE, 2008, Atlantic City, New Jersey. Proceedings... Disponível em: http:// w w w. vi n . c o m/ M e m b e r s/P r o c e ed i n g s / Proceedings.plx ?CID $=$ acvc $2008 \& P I D=p r 26048 \& O=V I N$. Acesso: 16 nov. 2009.

YAGER, J.A.; SCOTT, D.W. The skin and appendages. In: JUBB, K.V.F. et al. Pathology of domestical animals. 4.ed. California: San Diego, 1992. V.1, p.532-378.

YU, R.C. et al. A histopathological study of 643 cutaneous horns. British Journal of Dermatology, v.124, n.5, p.449452, 1991. 